\title{
An on-line computer system for hospital bacteriology: description of its development and comments after five years' use
}

\author{
JN BLAIR, PP BROWN
}

From the Department of Bacteriology, Queen Elizabeth Hospital, Birmingham B15 2TH

SUMMARY The development over several years of a computer system for hospital bacteriology $\frac{?}{0}$ reporting is described. The system was developed from a manual method to a punch-card batch $\dot{\omega}_{\perp}$ processing system and finally to a real-time on-line system. The value of the system to the clinical $\overrightarrow{0}$ departments and laboratory is discussed.

Apart from minor defects the system has been of immense advantage to all who make use of its $\vec{\omega}$ facilities.

It is generally agreed that in hospital laboratory computing, data acquisition is a more straightforward task than data processing. ${ }^{12}$ Whereas in the fields of clinical chemistry and haematology there has been great emphasis on automated means of data acquisition, computing in the bacteriology laboratory is concerned predominantly with data processing.

It is significant that a variety of methods have been attempted. The more recent ones include those of Harvey et al., ${ }^{3}$ who use numerically coded work sheets and paper tape with a GPO link to a timesharing Univac 1108 Computer; the use of preprinted mark-sensed cards $;{ }^{4}$ preprinted mark-sensed work sheets; $;$ a modified NCR request form plus paper tape; ${ }^{6}$ Port-a-Punch cards in combination with paper tape $;^{7}$ batch input using a mixture of three-character alphanumeric codes and numbers based on paper tape produced by teletypes $; 8$ use of optical mark reader forms as work sheets, with automatic validation and release of most reports; ${ }^{9} \mathrm{a}$ MUMPS based system using VDUs and mnemonic codes for data input. ${ }^{10}$

During the past ten years the reporting system of the Queen Elizabeth Hospital Bacteriology Laboratory has evolved from an entirely manual method to a punch-card batch-processing system and finally to a real-time on-line system.

ORIGINS OF COMPUTING AT QUEEN ELIZABETH MEDICAL CENTRE (QEMC)

In 1966 a grant of $£ 60000$ was made by the Nuffield Provincial Hospital Trust to support the rental of

Accepted for publication 23 March 1981 equipment suitable for medical computing. An IBM 1440 system was installed in the Medical School and $\frac{0}{0}$ the first hospital application was a punch-card $\stackrel{\mathbb{}}{-}$ record of the registration, transfer and discharge of $\vec{\oplus}$ all in-patients at the Queen Elizabeth Hospital.

Until this time the results of all bacteriolog investigations were recorded in the traditional way $\frac{0}{7}$ namely, handwritten on a large request card and transcribed by typist onto headed paper. Approximately 80 specimens were handled each day.

In 1967 the Department of Health and Social Security (DHSS) approved a grant to investigate the feasibility of using the IBM 1440 computer to record and print the routine results produced by the Bacteriology Department.

DATA PROCESSING IN BACTERIOLOGY

During 1968 a system was evolved whereby cards which were printed to serve as pathology request $\delta$ cards were prepunched with patient identity in the Registration Department.

The results of all laboratory investigations were coded and at the same time preprinted laboratory work cards were designed to receive the coded results. Identification details were duplicated from $\sigma$ the request card.11

Simultaneously validation, decoding and printing programmes were written so that the final production of the reports was made via the IBM 1440 computer.

By the end of 1968 the reporting of results of all routine work done in the Department of Bacteriology was done by computer. A discussion of the experience gained, problems encountered and some of the initial benefits which accrued may be found in 1132 
Whitby and Blair, 1972.12

Meanwhile in 1968, the DHSS initiated and financed a programme using advanced computing methods. Design proposals for a real-time system for the QEMC were completed by February 1970. Authority to go out to tender was given in January 1971 and a Univac 418111 Computer and associated hardware(see Appendix) was installed in March 1972.

The bacteriology system is an integral part of the on-line computer system at the QEMC which, in addition to the service to the laboratories provides an administration system, nursing orders and information systems. It is not possible to dissect out the cost of the bacteriology on-line system and consequently a financial comparison with the original manual method of reporting is not feasible. The departmental typist was replaced by a VDU operator. This policy was adopted by all laboratories so forming a pool of VDU operators to deal with all pathology requests and reports.

\section{Development of an on-line system in bacteriology}

The design of an on-line real-time system for the laboratories began in 1971. A widely based laboratory user group was established and small working parties composed of appropriate laboratory representatives and members of the computer unit met at frequent intervals during 1971 and 1972. Controversial points were referred to the Medical and Nursing User Groups.

By the autumn of 1974 the programming of the bacteriology real-time system was complete. To carry out a trial run all requests issued by six selected representative wards (about 35 per day) together with about 15 requests from external sources were intercepted during booking in and processed each day. The trial ran for eight weeks and incorporated several file housekeeping and archiving runs. In spite of rigorous and lengthy testing, however, inevitably some faults remained and in fact, within the first four weeks after "going live" 25 minor faults or problems were identified.

\section{OPERATION OF THE SYSTEM}

The bacteriology real-time system became operative in April 1975 (see Figure). There are ten bacteriology files, a further eight files are shared by the bacteriology system and six additional files are accessed.

\section{Confidentiality}

Access to the computer through the VDU keyboard is preceded by logging-in. Each authorised user has a unique log-in code. Different grades of log-in code determine, firstly, what parts of the real-time system are accessible to the user, and secondly, what, if any,

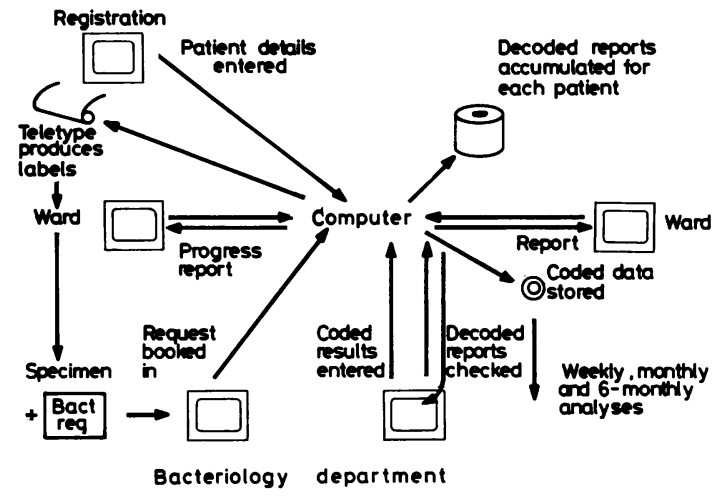

impact the user can have on a patient's record. For example, in the Bacteriology Department bookingin and reporting results can be done only by the VDU operators; accepting or rejecting bacteriology reports only by medical personnel or senior technicians; but all technicians can call up and examine all laboratory reports, ward lists and so on.

After logging-in, the appropriate part of the realtime system, and finally the required screen, is obtained by selecting one choice from a series of successively narrowing choices.

An early criticism of the confidentiality of the realtime system was that one consultant was able to examine another consultant's patient's results. This facility, however, is generally considered beneficial rather than the reverse.

A more real problem is the visual display screen left on after logging-in, where all information appropriate to the initial user is accessible. Education and discipline in VDU use is required in such cases. Changes in staff and student users can make this a constant requirement. If necessary, occasional highly confidential reports of well-known patients are not put into the computer. The consultant sends a typed report in an envelope.

\section{Procedure for receiving bacteriology specimens and} booking the requests into the real-time system At the time of admission 20 adhesive identity labels are produced and 40 small labels with abbreviated identification, designed for use on request cards and specimen containers respectively, are similarly produced by the line printer in the Registration Department. These accompany patients to the wards.

Preprinted bacteriology request cards are kept on the wards. Clinical and other details are entered by hand at the time of use, one identity label being attached to the card and a corresponding smaller one to the specimen container. One card accompanies each specimen to the laboratory. 
Here, the appropriate preprinted laboratory work card is selected. The cards used in the punch-card system were adopted with only minor layout changes. Keying in the registration number and check digit (the check digit is calculated by the computer using Modulus 11 and weightings range 1-10, which eliminates the occurrence of undetected keying error) produces the patient's identity details on the screen. To this is now added the type of work card, specimen code number ${ }^{11}$ and laboratory number.

The time taken to book in a batch of requests depends on whether these are from registered or nonregistered patients (approximately 2 minutes and 3 minutes respectively, to book in 10). It is also influenced by the response time, which may vary from almost instantaneous to approximately 8 seconds; and to a small extent by the operator. Approximately $26 \%$ of the requests received are from non-registered patients. Between 1968 and 1976 the work load had almost doubled so that each day approximately 150 requests are now dealt with. The computer compiles and prints daily an alphabetical list of all requests received. There is also an alphabetical list of reports dispatched.

\section{Recording and entering results}

As work proceeds, the cards are completed in code by the technicians. Should culture produce significant growth another and different card is used to enter the diagnostic tests and antibiotic sensitivities for each organism isolated.

The cards are collected in batches by the VDU operators. The coded results are entered through the VDU. In addition, facilities are available for comment on each report, either by selecting a coded commonly used expression, or by keying in free text up to 40 spaces. The time taken varies with the type of result, and as with booking-in, it is also influenced by the response time and to a small extent by the operator. (Approximately 2 minutes for 10 negative reports, 6 minutes for 10 positive reports.) A progress report for specimens still in the laboratory is available.

\section{Discussion}

Errors may occur in the ward, during booking-in, at the bench and during reporting. Sophisticated validation checks minimise the chance of undetected errors. During booking-in there is a detected error rate of approximately $2.6 \%$. The most frequent error is wrong keying of the laboratory number. The errors detected by the validation checks during reporting are approximately $1.3 \%$. However, sensible but wrong reports can only be detected by visual comparison of each work card with its final report on the screen. Every report is checked in this way before being released. Checking is facilitated by dealing with reports in batches. The first report is displayed on the screen when its laboratory number is keyed in and subsequent reports appear automatically, as each previous report is released.

The validity checks are concerned essentially with the mechanics of transferring information-for example, misreading, transposition, wrong keying, and relatively little with the bacteriological content of the report. To incorporate such aspects of checking would have unacceptably increased the initial programming time.

The "limits" system of quality control and pattern 웅 recognition established by Lindberg ${ }^{13}$ illustrates some $\omega$ of the safeguards which can be incorporated. Petralli14 likewise has incorporated a quality control program into the recording of antibiotic sensitivity testing. It is estimated that the computer detects and corrects 16 sensitivity errors in each 100 isolates. The time-sharing system described by Harvey et $\mathrm{al} .^{3}$ not only checks for mistakes but generates interpretative comments derived from an analysis of test results. The bacteriological validation described by Williams et al. ${ }^{9}$ enables the majority of reports to be released automatically. Lapage's comprehensive scheme for the identification of bacteria by cone puter, ${ }^{15-19}$ while scarcely applicable to the routine isolates, further illustrates the potential of a real-time bacteriology system.

\section{PROBLEMS}

The problems associated with the coding of the very variable and largely non-numeric results have already been discussed. ${ }^{12}$ The introduction of the real-time system has accentuated other potential limitations such as reduced departmental autonomy. The dependence on highly sophisticated equipment for booking-in specimens, reporting, checking and distribution of reports makes the department more vulnerable than when reports were produced manually. The system is based on a single processor. The computer functions at $99 \%$ reliability. Minor

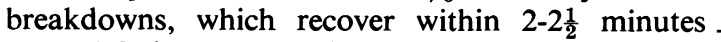
occur 1-2 times per week. Major breakdowns occur 1-2 times per month. Defects in the air conditioning supplies cause the majority of close downs. During major breakdowns, no booking-in, reporting results or distribution of reports is possible through the realtime system. Urgent reports are telephoned and there is a distribution of typed reports by porter. The impact of a breakdown depends crucially on the time of day. A breakdown during the peak work period in the morning might involve a 1-2 hour period of catching up during the afternoon, while an afternoon breakdown would have virtually no

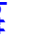


impact on the bacteriology system. With a few exceptions (Saturday mornings) catching up has always been completed the same day. There is at all times a Univac engineer either on site or on call. The real-time day, originally 14 hours, now extends from 5.00 a.m. to 11.00 p.m., including Sundays and Bank Holidays. Opit ${ }^{20} 21$ concluded that the inability to provide a 24-hour service contributed to the unacceptability of their real-time system to the ward staff.

The design of the system, with cumulative patient reports, is based on the assumption that the great majority of requests are from in-patients (the outpatient department is situated in another hospital in the city). Out-patient reports and those, for whatever reason, lacking a registration number, are kept on a separate computer file. After being accepted, these are available on-line only in coded form, for up to two weeks, or until the external patients' file is full. The very limited time that non-registered reports are available on-line causes complications where there is a further report to follow the initial one-for example, where a TB culture report follows after eight weeks. Once a report has been accepted it is accessed to the appropriate patients' file. It is not possible, thereafter, to erase subsequently discovered errors. With the passage of time it is getting progressively more difficult to make additions-for example, new antibiotics, or longer comments, as the allotted file space gets used up. Bacteriology was the first of the pathology departments to have a real-time system. In spite of good rapport with the computer unit and advice from specialist working parties throughout the design phase, some of the present deficiencies are due to initial lack of effective communication. There is a central support team, but it is inevitable that some of the desired changes have to be deferred until developmental work on other systems is complete.

\section{BENEFITS}

The benefits of the real-time bacteriology system are associated primarily with the users of the laboratory rather than with the laboratory itself. One exception has been the introduction of a module for the assay of aminoglycoside antibiotics. Zone sizes for standard and test serum from plate assays are entered and the most appropriate curve and the result in $\mu \mathrm{g} / \mathrm{ml}$ together with the standard deviation (SD) are produced on the screen. The more sophisticated data retrieval made possible by the advanced computer installation benefits both. Reports are available to all VDU users immediately they have been checked. The significance of this varies but all very urgent results are telephoned-for example, results on patients suspected of meningitis. Cumula- tive reporting also varies in its degree of usefulness. It is particularly useful in patients with prolonged mixed or severe infections. Reports of registered patients remain available on-line for 50 days after discharge. Access to these reports is simple, quick and unequivocal and greatly preferable to a manual search. After this period reports are transferred to archive tapes. Reports from Renal Unit patients and leukaemia patients, however, are available on-line indefinitely. Reports have improved in terms of identification and presentation. Both booking-in and reporting is significantly quicker than with the manual method and similar to the punch card method. The real-time reports, however, are available immediately they have been checked and accepted, instead of at the end of the day. The use of the progress report has diminished, but not eliminated, telephone enquiries to the laboratory.

USE OF DATA MADE AVAILABLE VIA THE

UNIVAC SYSTEM

The information can be conveniently grouped into that used primarily by members of the laboratory; that requested by individuals wards and that made available to the Queen Elizabeth Hospital as a whole.

This is a selection of some of the more interesting observations which we can now regularly undertake. A record is kept of all organisms isolated with their source. This list is printed weekly and is available on Monday mornings. There is a weekly list of all Staphylococcus aureus isolations with their phage pattern and source. Antibiotic sensitivity patterns of individual organisms are constantly monitored. Tables are compiled of all commonly isolated organisms. Where appropriate, patient details are included (eg, Pseudomonas) or selective patient details (eg, Klebsiella blood cultures, or multipleresistant isolations). These tables are produced routinely each quarter from the coded Fortranaccessible file (see Figure) but if necessary relevant information can be produced overnight. A record of all blood cultures is kept. Summary tables show organisms isolated and number per ward. Incidence of bacteraemia in terms of sex, age groups, interval after admission, medical, surgical, renal unit, can be assessed. Summaries of all urine cultures show number per ward with $>10^{5}$ organisms $/ \mathrm{ml}$, percentage with WBC $>10 / \mathrm{mm}^{3}\left(>0.01 \times 10^{9} / \mathrm{l}\right)$, and all organisms isolated. Wound infection can be determined for selected operations in relation to length of stay, consultant, ward and organisms isolated. These records provide an internal means of quality control as well as supplying relevant information for epidemiology and hospital cross infection. 
Where an experimental rotation of antibiotics is in use, in certain wards sensitivities for the ward and chosen control ward are supplied. Relevant information is supplied where there is a suspected crossinfection problem.

Through the visual display screens the following information is available on-line to the hospital. The screens are updated quarterly, and show the last four quarters so that any trend can be observed: current sensitivity patterns for the most frequently isolated organisms for QEH; sensitivity patterns of the most common organisms isolated from sputum; susceptibility of urinary pathogens to various antibacterials; common isolations from urine culture; sensitivity patterns of the most common organisms isolated from urine; and information screens with details of the type of specimen required for various investigations-that is, a House Officer's guide to the use of the facilities available in the Bacteriology Department.

The stored information can be recalled in many different ways depending upon the individual requirements of those concerned. We have listed some of the uses which we regularly make available. There can be no doubt as to the value of the system; such information as is available could not be utilised in this way without a computer system. The acceptability to all groups of laboratory staff has been mainly due to the fact that those who were to operate it were involved in its design from the beginning. The co-operation of systems analysts and programmers, together with the robustness of the hardware, ensured its success.

\section{Appendix}

The computer system at the Queen Elizabeth Medical Centre, Birmingham, serves the needs of a 620-bed teaching hospital and medical school, a 196bed maternity hospital and, off-site, a 212-bed children's hospital.

\section{Main storage}

The central processor unit is a UNIVAC 418111 , core size $131 \mathrm{~K}$ words, word size $18 \mathrm{Bit}$. The cycle time is $\mathbf{7 5 0}$ nanoseconds. It has Assembler, Fortran and Cobal language processors. Assembler is used for operating the real-time system. The retrieval programmes are in Fortran. The maximum number of multiprogrammed runs is 10 .

\section{Mass storage}

There are 6 (1600 BPI) U12 tape handlers, 2 (4.25 ms access time) Drums, and 16 (30 ms access time) Disk drives.
Sub-systems

Two 9300 card reader, card punch, line printer $(8 \mathrm{~K}$ Byte memory).

\section{Communications}

There is a one VDU control unit capable of handling 256 VDUs. Currently 60 VDUs are distributed around the hospitals and wards, laboratories, offices and operating theatres. There is one communications terminal module controller capable of handling up to 64 teletypes, one teletype control unit $\vec{\nabla}$ and one manual teletype patch board. There are 21 (10 cps, 100 Baud) Olivetti teletypes and $6(30 \mathrm{cps}$, 300 Baud) Univac DCT 500 teletypes distributed around the hospitals.

\section{References}

1 Abson J, Prall A, Wootton IDP. Data processing in pathology laboratories: the Phoenix System. Ann Clin $\omega$ Biochem 1977;14:307-29.

2 Anonymous. Hospital laboratory computing. $\mathrm{Br} \mathrm{Med} \mathrm{J}$ 윽 $1978 ; \mathrm{i}: 387$.

3 Harvey KJ, Were M, Heys W, Smith DD. A time-shared computer system for data processing in bacteriology. Med J Aust 1972;2:1076-80.

4 Ayliffe PF, Chalke R. A computer system to perform record handling and reporting for a hospital microbiology laboratory. Med Lab Technol 1973;30:363-71.

5 Andrews HJ, Vickers M. An assessment of one year of computer-assisted microbiology reporting at Charic Cross Hospital. J Clin Pathol 1974;27:185-91.

6 Farrar JL, Brogan TD, Moulding T, Taylor R, Page 遮 Use of a computer for producing microbiological reports and for data storing and processing. J Clin Pathol 1975;28:580-6.

? Goodwin CS, Smith B Clare. Computer printing and filing $\mathbb{D}$ of microbiology reports. Description of the system. $\vec{F}$ $J$ Clin Pathol 1976;29:543-52.

8 Mitchison DA, Darrell JH, Mitchison Ruth. A computerassisted bacteriology reporting and information system. $J$ Clin Pathol 1978;7:673-80.

9 Williams KN, Davidson JMF, Lynn R, Rice E, Phillips I. A computer system for clinical microbiology. J Clin Pathol 1978;12:1193-201.

${ }^{10}$ Ridgway GL, Batchelor J, Luton A, Barnicoat M. Data processing in microbiology; an integrated, simplified system. J Clin Pathol 1980;33:744-9.

11 Whitby JL, Blair JN. A computer-linked data processing system for routine hospital bacteriology. In: Baillie A, o Gilbert RJ, eds. Automation, mechanisation and data. handling in microbiology. Society for Applied Bacteriology Technical Series No 4. London'\& New York: Academic Press, 1970:23-32.

12 Whitby JL, Blair JN. Data processing in hospital bac- $\mathcal{O}$ teriology: experience of 18 months' trial. J Clin Pathol N 1972;25:338-43.

${ }^{13}$ Lindberg DAB. The computer and medical care. Illinois: $\mathrm{N}$ Thomas CC, 1968.

${ }^{14}$ Petralli J, Russell E, Kataoka A, Merigan T. On-line computer quality control of antibiotic sensitivity testing $N$ Engl J Med 1970;283,14:735-8.

15 Lapage SP, Bascomb S, Willcox WR, Curtis MA. Computer identification of bacteria. In: Baillie A, Gilbert RJ, eds. $\square$ Automation, mechanisation and data handling in microbiology. Society for Applied Bacteriology Technical $\overrightarrow{\mathbb{D}}$ 
Series No 4. London \& New York Academic Press, 1970: $1-22$.

16 Lapage SP. Thoughts on screening tests in bacteriology. J Clin Pathol 1971 ;24:404-8.

${ }^{17}$ Lapage SP, Bascomb Shoshana, Willcox WR, Curtis MA. Identification of bacteria by computer. General aspects and perspectives. J Gen Microbiol 1973;77:273-90.

18 Lapage SP, Bascomb Shoshana, Willcox WR, Curtis MA. Identification of bacteria by computer. Identification of reference strains. J Gen Microbiol 1973;77:291-316.

19 Lapage SP, Bascomb Shoshana, Willcox WR, Curtis MA.
Identification of bacteria by computer. Theory and programming. J Gen Microbiol 1973;77:317-30.

${ }^{20}$ Opit LJ, Woodroffe FJ. Computer-held clinical record system. Description of system. Br Med J 1970;iv:76-9.

${ }^{21}$ Opit LJ, Woodroffe FJ. Computer-held clinical record system. Assessment. Br Med J 1970;iv:80-92.

Requests for reprints to: Dr PP Brown, Department of Bacteriology, Queen Elizabeth Hospital, Birmingham B15 2TH, England. 